Was ist der Ausweg, wie können Risiken vermieden werden? Der ungewollte Statutenwechsel mit unbekannten Rechtsfolgen kann verhindert werden, wenn eine ausdrückliche Rechtswahl zu Gunsten des deutschen Heimatrechts getroffen wird. Dies ist gemäß Art. 23 der Erbrechtsverordnung möglich und kann in einem Testament oder Erbvertrag erfolgen. Es muss durch ausdrückliche Erklärung in Form einer Verfügung von Todes wegen die gesamte Erbfolge dem Recht des Staates unterstellt werden, dem er angehört. Auch eine vor Inkrafttreten getroffene Rechtswahl bleibt wirksam, soweit sie nach Art. 17 der Erbrechtsverordnung zulässig ist.

Dann gilt auch für im europäischen Ausland lebende deutsche Staatsangehörige das Heimatrecht. Dies gilt natürlich auch für ausländische Staatsangehörige in Deutschland.

Eine auf deutsches unbewegliches Vermögen beschränkte Rechtswahl gem. Art. 25 II EGBGB wird dann allerdings nicht mehr anerkannt werden.

Auf Antrag der Beteiligten kann sich ein ausländisches Gericht bei getroffener Rechtswahl für unzuständig erklären, wenn nach seiner Auffassung die Gerichte des Mitgliedstaates der Rechtswahl die Erbsache besser entscheiden können.

Bei bestehender Rechtswahl können die betroffenen Parteien - die Erben - auch eine Gerichtsstandsvereinbarung treffen.

Auf den ersten Blick tritt eine Vereinfachung für Deutsche, die in Europa mobil sind, ein.

Bei Unkenntnis der Rechtslage, insbesondere des Rechts des Landes in dem man sich zeitweilig aufhält, können jedoch zahlreiche Probleme auftreten.

Wesentlich wird in der verbleibenden Zeit bis zur Anwendung des Rechts sein, dass ein hohes Maß an Information besteht und alle BeraterInnen aufgefordert werden die Chancen aber auch die Risiken öffentlich zu machen.

Hinweise auf die bestehenden Vermögensunterschiede von Männern und Frauen um eine geschlechtergerechte Gesellschaft zu ermöglichen, können dabei nicht Schaden. Jedenfalls sollten wir versuchen hier Einfluss zu nehmen, dass sich diese Unterschiede angleichen.

Und hierzu möchte ich Sie alle herzlich ermutigen.

\title{
Europawahl am 25. Mai 2014 - Gehen Sie wählen?!
}

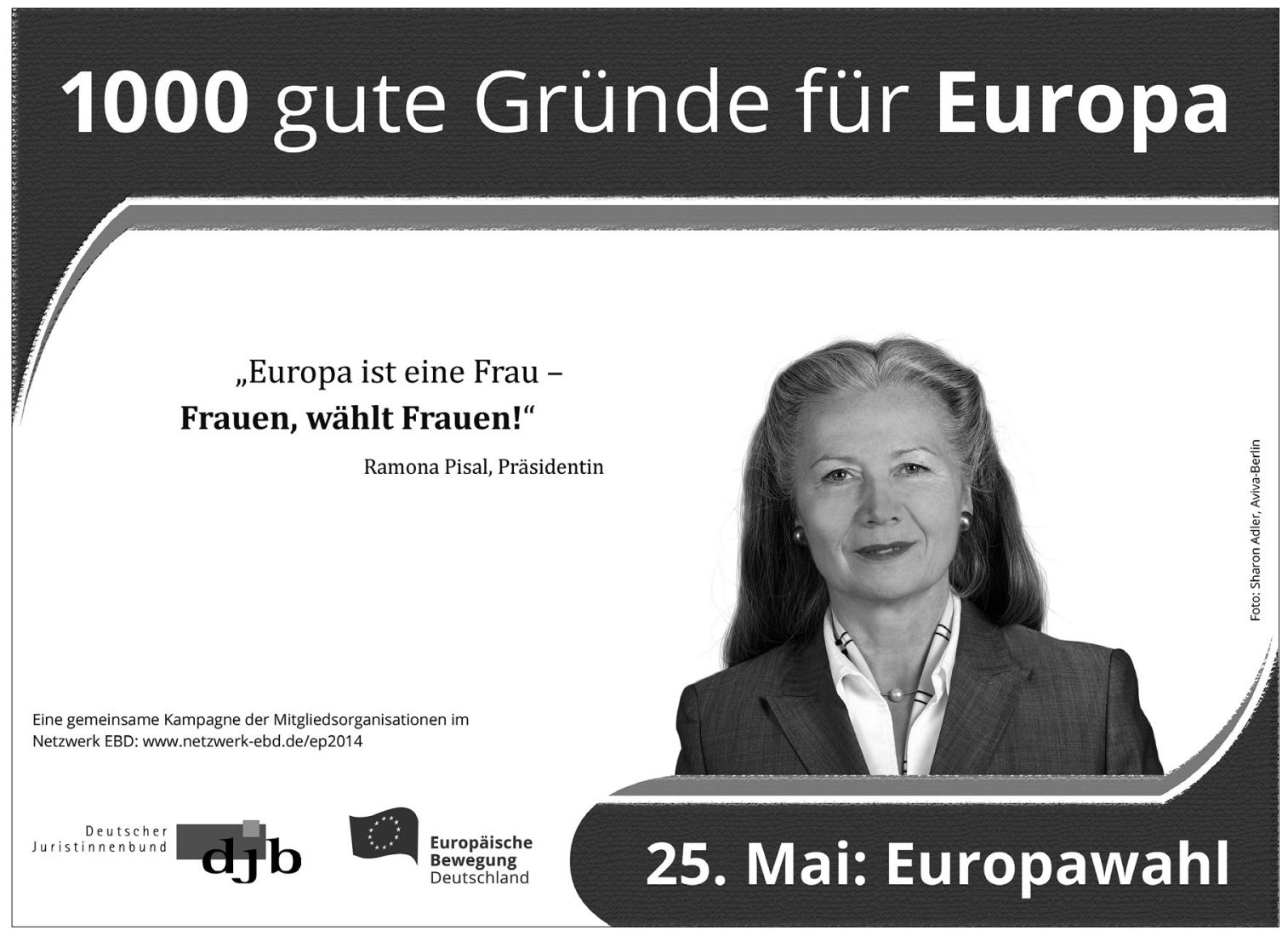

Die Gleichstellung der Geschlechter ist ein Politikfeld, das sich durch den Einfluss des Europäischen Parlamentes dynamisch entwickelt hat. Deshalb engagiert sich der djb bei der Wahlaufruf-Kampagne der Europäischen Bewegung Deutschland (EBD) (www.europaeische-bewegung.de).Nach dem Vorbild der
Netzwerk-Kampagne zur Europawahl 2009 hat die EBD auch im Wahljahr 2014 ihre Mitgliedsorganisationen um zielgruppenspezifische, klare Aussagen gebeten: Warum ist das Europäische Parlament von Bedeutung für die jeweilige Organisation und warum sollen die Leserinnen und Leser zur Wahl gehen? 